\title{
Review \\ Sustainable Processes in Aluminium, Magnesium, and Titanium Alloys Applied to the Transport Sector: A Review
}

\author{
David Blanco $^{1, *}++^{\mathbb{D}}$, Eva María Rubio ${ }^{1} \mathbb{D}$, Raquel María Lorente-Pedreille ${ }^{2} \mathbb{D}$ and María Ana Sáenz-Nuño ${ }^{2}(\mathbb{D}$ \\ 1 Department of Manufacturing Engineering, Industrial Engineering School, Universidad Nacional de \\ Educación a Distancia (UNED), St/Juan del Rosal 12, E-28040 Madrid, Spain; erubio@ind.uned.es \\ 2 Mechanical Engineering Department, ICAI, Comillas Pontifical University, Alberto Aguilera 25, \\ E-28015 Madrid, Spain; rmlorente@comillas.edu (R.M.L.-P.); msaenz@iit.comillas.edu (M.A.S.-N.) \\ * Correspondence: dblanco78@alumno.uned.es; Tel.: +34-913-988-226 \\ † Programa de Doctorado en Tecnologías Industriales.
}

check for

updates

Citation: Blanco, D.; Rubio, E.M.;

Lorente-Pedreille, R.M.; Sáenz-Nuño, M.A. Sustainable Processes in Aluminium, Magnesium, and Titanium Alloys Applied to the Transport Sector: A Review. Metals 2022, 12, 9. https://doi.org/10.3390/ met12010009

Academic Editor: Christian Mittelstedt

Received: 19 November 2021 Accepted: 20 December 2021 Published: 22 December 2021

Publisher's Note: MDPI stays neutral with regard to jurisdictional claims in published maps and institutional affiliations.

Copyright: (c) 2021 by the authors Licensee MDPI, Basel, Switzerland. This article is an open access article distributed under the terms and conditions of the Creative Commons Attribution (CC BY) license (https:// creativecommons.org/licenses/by/ $4.0 /)$.

\begin{abstract}
The reduction of consumption and pollutant emissions is a top priority for the transport sector. One working line is the substitution of conventional structural materials with lightweight materials such as metallic alloys of aluminium, titanium, and/or magnesium. For this reason, and considering that the number of related articles is lower than the existing number of other structural lightweight materials, it is considered very convenient and helpful to carry out a systematic analysis of their latest trends through Open Access literature. A methodology adapted from the PRISMA statement is applied, in order to guarantee unbiasedness and quality in selecting literature and research. The final selection is made up of the 40 most cited research papers from 2015-2020, with an average of 20.6 citations per article. Turning and drilling are the most trending machining processes, and there is particular interest in the study of sustainable cooling, such as dry machining, cryogenic cooling, and MQL. In addition, another trending topic is multi-materials and joining dissimilar materials with guarantees. Additive manufacturing has also been identified as an increasingly trending theme, appearing in $18 \%$ of the selected studies. This work is complemented with summary tables of the most cited Open Access articles on sustainable machining and cooling, multi-materials or hybrid components, and additive manufacturing.
\end{abstract}

Keywords: lightweight; magnesium; aluminium; titanium; multi-material; aerospace; automotive; sustainable; trends

\section{Introduction}

Transport is responsible for more than $30 \%$ of $\mathrm{CO}_{2}$ emissions in the European Union (EU); $72 \%$ comes from road transport, $13.6 \%$ from maritime industry, $13.4 \%$ from civil aviation, and $1 \%$ from rail transport and others. The EU has committed to reducing emissions from transport by $60 \%$ by 2050, compared to 1990 levels [1].

Regarding road transport, new cars sold in 2017 emitted on average $118.5 \mathrm{~g} \mathrm{CO}_{2} / \mathrm{km}$, i.e., an increase compared to 2016 of $0.4 \mathrm{~g} \mathrm{CO}_{2} / \mathrm{km}$. On the other hand, the mass of vehicles strongly influences their consumption and pollutant emissions. The average mass of new cars sold in 2017 in the EU was $1390 \mathrm{~kg}$. The mass of an average diesel car sold in 2017 was $20 \mathrm{~kg}$ lower than in 2016 [2]. On the other hand, $\mathrm{CO}_{2}$ emissions from heavy-duty vehicles, such as trucks, buses and coaches, represent about $6 \%$ of total EU emissions and $25 \%$ of road transport emissions, and are expected to increase by $9 \%$ between 2010 and 2030 [3]. Concerning legislation, the average $\mathrm{CO}_{2}$ emissions of new passenger cars registered in the EU must decrease by $15 \%$ by 2025 and by $30 \%$ by 2030, compared to 2021 data. These requirements imply an increase in the manufacturing cost of a new car of about EUR 1000 per year by 2030. However, this cost is much lower than the fuel savings over the lifetime of the vehicle. Most cars today are powered by combustion engines, and it is expected that at least $80 \%$ of the new car fleet in 2030 will still use a combustion engine [4]. 
As for the aviation sector, the worldwide aviation industry produces about $2 \%$ of all human-generated carbon dioxide emissions [4,5]. On the other hand, the EU air transport sector directly employs between 1.41 and 2.02 million people and supports between 4.83 and 5.54 million jobs globally, contributing directly to the gross domestic product (GDP) with EUR 110,000 million. Its global impact, tourism included, reaches EUR 510,000 million [6]. In 2001, the Advisory Council for Aviation Research and Innovation in Europe (ACARE) was created, and among its most important objectives are the reduction of $\mathrm{CO}_{2}$ emissions by $75 \%$ compared to 2000 data, and the design of aeroplanes to optimise their recycling [7]. In the design of fuselages and cabin interiors, it is essential to promote lightweight structural materials. Their use will require new design and manufacturing methods, with multifunctional materials and structures to save weight and reduce manufacturing costs, seeking high recyclability and reusability [8]. With these requirements, the aircraft industry is making significant efforts towards sustainability. For example, each new generation of Boeing aircraft is between $15 \%$ to $25 \%$ more efficient than the previous one [9]. Regarding Airbus, the A350 model is made of 53\% lightweight and composite materials, and saves $25 \%$ of fuel compared to the previous model, and the A220 family of aircraft is the most efficient in its class [5]. New production methods, such as 3D printing, help to produce lighter parts with significantly less waste, and help to reduce consumption. Together with Tarmac Aerosave, Airbus reuses or recycles up to $92 \%$ of its aircraft. Emissions of volatile organic compound (VOC) were reduced by 60\% from 2006 to 2017. These innovative solutions aided Airbus in reducing greenhouse gas emissions up to 14\% between 2006 and 2017 [5,10]. On the other hand, the Intergovernmental Panel on Climate Change (IPCC) is the United Nations body charged with assessing the science related to climate change. In October 2018, the IPCC published a special report on the impacts of global warming of $1.5^{\circ} \mathrm{C}$ above pre-industrial levels to support the Paris Agreement process. This report estimated that climate warming due to human activities is increasing by $0.2{ }^{\circ} \mathrm{C}$ per decade. To stabilise, global net $\mathrm{CO}_{2}$ emissions from human activities would need to reach net zero by 2050 [10,11]. For this reason, in 2019, all airlines worldwide with international routes started to officially track and communicate their emissions, following the guidelines defined by the Carbon Offsetting and Reduction Scheme for International Aviation (CORSIA), approved by the International Civil Aviation Organization (ICAO) of the United Nations in $2016[5,9]$.

Maritime transport is responsible for approximately 940 million tons of $\mathrm{CO}_{2}$ emissions annually, accounting for around $2.5 \%$ of worldwide greenhouse gas emissions (GHG). If no new measures are implemented, it is estimated to increase from $50 \%$ to $250 \%$ by 2050. The International Maritime Organization (IMO) has set targets to reduce annual GHG emissions from shipping by at least $50 \%$ by 2050, compared to 2008 levels [12]. The IMO has established guidelines for the consumption of each type of ship according to its cargo capacity, and newly built ships will have to adapt to these regulations, which will become progressively more stringent over time. For example, by 2025, all new ships must be 30\% more efficient than those manufactured in 2014 [13]. By transferring Airbus expertise in aeronautics to shipping, AirSeas is expected to enable ship owners to reduce fuel consumption and $\mathrm{CO}_{2}$ emissions by $20 \%$ [5].

On the other hand, it is inevitable to mention the effect that the COVID-19 pandemic has caused on transportation-related sectors. In the aviation sector, compared to 2019, the year 2020 experienced a reduction of 2.7 billion passengers and losses of USD 371 billion, and forecasts indicate that in 2021 there will be a reduction of between 1.9 and 2.4 billion passengers, and losses between USD 282 and 343 billion. [14]. In the automotive sector, production losses in the EU due to COVID-19 amounted to 4,024,036 motor vehicles from January 1 to September 30, 2020. This quantity represented $22.3 \%$ of total EU production in 2019. The jobs of at least 1,138,536 Europeans working directly in automotive manufacturing were affected by factory closures as a result of the pandemic, and the impact on the automotive supply chain, in general, has been even more critical [15]. 
As previously stated, the need to reduce energy consumption, and therefore pollutant emissions, is one of the critical targets for transport-related sectors, such as the aeronautical, automotive, or maritime industries. An important research line is focused on reducing the mass of vehicles and ships through components made of light metal alloys. Within this range of alloys, aluminium, titanium, and magnesium alloys stand out for their excellent weight/strength ratio. Moreover, these alloys can be combined with one other or with other light and resistant materials to create hybrid structures, offering the combined advantage of low weight and high strength while maintaining good wear and fatigue characteristics [16-18], although it is estimated that the maximum reduction in environmental impact by reducing vehicle mass is limited to $7 \%$ [19].

Aluminium alloys are characterised by their light weight, corrosion resistance, and good thermal and electrical conductivity. Their mechanical properties at room temperature, such as tensile strength, yield strength, and modulus of elasticity, are moderate, and their fatigue strength is acceptable. They are materials that are widely used in lightweight structural parts for the automotive and aerospace industries [16,20], and the transportation industry is responsible for $35-40 \%$ of their total consumption [21]. They are frequently applied through aluminium matrix composites (AMMs); these multi-materials have superior corrosion, wear, electrical, temperature, and elastic modulus properties compared to conventional alloys, and good cost/strength ratios, which make them good candidates for aerospace, automotive, chemical, and transportation applications, where, for example, in the case of the transportation industry, their use is forecast to double by the year 2025 [22,23]. In addition, they are also frequently used associated in multi-material composites with steels [24], FRPs [25], magnesium [17], and titanium [16].

Concerning magnesium alloys, magnesium is a metal with many advantages of use. It is very abundant, representing $2.7 \%$ of the earth's crust, and it can be produced from seawater with a purity of $98.8 \%$. Its density is $66 \%$ that of aluminium and $25 \%$ that of steel, making it an ideal candidate to replace them. Magnesium is the lightest structural alloy on the planet, but its use is limited by its low formability. In machining processes, the forces and temperatures in the cutting zone are low. In addition, its chips are short, and tool life is long, so it is considered an easy material to machine and a good candidate for machining through sustainable cooling/lubrication. However, it is a material that presents some drawbacks, such as the risk of ignition from $450{ }^{\circ} \mathrm{C}$ and the risk of explosion when it is in powder form. It generates flammable and potentially explosive hydrogen atmospheres when reacting with water, so it is of interest to reduce the use of water-based coolants [18]. There is a lot of literature associated with its use in companies in the automotive sector, and it is currently used by automotive companies such as Volkswagen, General Motors, Ford, Toyota, and BMW to manufacture some of their components [26].

Regarding titanium alloys, they are characterised by light weight, high wear and corrosion resistance, and a great ability to maintain high strength at high temperatures; however, their low thermal conductivity and high reactivity make them tend to produce premature tool wear, so they are considered a difficult material to machine $[27,28]$. It is estimated that Ti6Al4V alloy represents $50 \%$ of the global production of titanium metal, and $80 \%$ of this corresponds to the aerospace and medical industries [28,29]. Titanium is a material with a clear interest in being recycled, reused, and manufactured in near-final forms because of its environmental impact when using primary material [30,31].

On the other hand, in studies performed on existing studies, not all publications, papers, or research articles provided similar reliability, methodological quality and interest [32]. For this reason, a methodology adapted from the PRISMA statement to the field of engineering was established. The objective is to limit possible biases in selecting and analysing scientific literature to provide the most relevant and representative articles, with a contrasted quality, and transparent and uniform inclusion criteria. The resulting selection comprises the 40 most cited research papers over the period 2015-2020, with an average of 20.6 citations per article, according to information from the WoS search engine on 7 December 2021. 
Among the selection criteria adopted for the search were: Open Access literature, because it is a trend in academic evaluation $[33,34]$ that seeks to democratise access to knowledge and educational materials [35-38]; English-language publications, because it is the language employed in more than $90 \%$ of articles in science [39] and has the highest number of citations [40]; use of the Web of Science (WoS) repository, as it is the world's leading search platform for scientific citations and analytical information [41] and overlaps $94 \%$ of the citations included in Scopus in the engineering domain [42], and the average number of citations per year has been included as it is widely used and accepted as a bibliometric indicator [42-44].

The following conclusions can be drawn from the analysis: machining is included in $40 \%$ of the studies, and turning is the most trending topic found in $38 \%$ of the machining studies, followed by drilling in 31\%. In addition, $75 \%$ of the selected machining studies include sustainable cooling, 63\% dry machining, and 19\% cryogenic cooling and MQL. Moreover, studies on the replacement of conventional fluids by biodegradable oils are emerging. On the other hand, studies that include multi-material components are also growing in number. Within this group, the joining of dissimilar materials with $46 \%$, and the machining of multi-material composites with $38 \%$ of the multi-material articles, are identified as topics of special interest. Multi-material combination of metal-metal, with $62 \%$, appears in the most extensive number of studies on multi-materials, followed by AMMs, found in $31 \%$. Finally, additive manufacturing is another topic identified as a subject of current interest, appearing in $18 \%$ of the selected studies. The work is complemented by tables summarizing the main topics covered and the most cited articles on sustainable machining and re-cooling, multi-materials and additive manufacturing.

\section{Methodology for Article Selection and Analysis}

The methodology followed for the review and analysis of the literature published during 2015-2020 on lightweight aluminium, titanium, and magnesium alloys with potential application to the aeronautical and automotive fields, involving machining processes and/or innovative manufacturing processes, is described below. This methodology was established beforehand and applies to the selection and information analysis stages. The main objective is to minimise the probability of bias in the study. First, quality, inclusion and exclusion criteria are predefined. Then, keywords and resulting Boolean equations are defined. A search engine is predefined, and a search is performed by applying the Boolean equations and the predefined inclusion criteria. Afterwards, the application of the methodology carries out an initial preselection and an individual review of each preselected study, to ensure compliance with the inclusion criteria that make it possible to arrive at a final selection. In the case that a larger number of articles than necessary was obtained for the study, the papers with the highest average number of citations per published year are selected. Finally, the desired information is extracted through closed questions, and the information contained in the studies is analysed to answer the questions that gave rise to the research. The flow chart in Figure 1 shows the applied methodology graphically.

The purpose is to obtain a selection of relevant, comparable articles chosen based on pre-established criteria, and thus minimise the risk of bias in their choice or analysis by establishing protocols for all the decisions to make over the process. The Web of Science (WoS) database was defined as the search engine. This database is provided by Clarivate Analytics and allows for tracking more than 1700 million references cited in more than 159 million records [45]. 


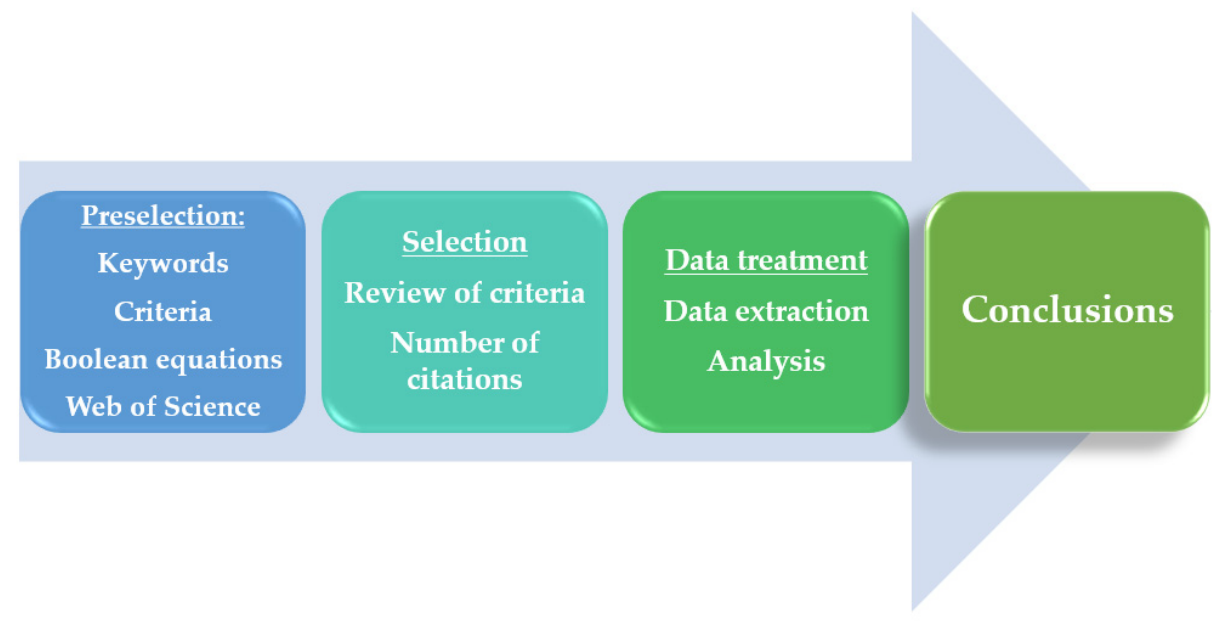

Figure 1. Stages of the applied methodology.

WoS is the world's leading search platform for scientific citations and analytical information. It is used as a research tool, supports a wide range of scientific papers from different disciplines, and allows the analysis of large-scale datasets. Therefore, it has been extensively employed in academic studies published over the last 20 years [41-43]. The choice of English as the language of publication is based on the fact that in international journals more than $90 \%$ of the articles in the natural sciences are written in English, so many authors believe that it is necessary to publish in English, or even only in English [39]. Furthermore, articles published in non-English languages have fewer citations [40,42], so including articles in non-English languages may lead to heterogeneity in the selection, and the aim is to obtain a representative selection based on homogeneous selection criteria, so that we can analyse current trends. As a publication format, only Open Access publications are chosen. According to the declaration from the Budapest Open Access initiative in 2002, "Removing access barriers to this literature will accelerate research, enrich education, share the learning of the rich with the poor and the poor with the rich, make this literature as useful as it can be, and lay the foundation for uniting humanity in a common intellectual conversation and quest for knowledge." [37,38]. According to the Director of the Harvard Open Access Project, "open access is the convergence of tradition and a new technology, which makes a public good possible" [36]. The open access movement seeks to democratise access to knowledge and educational materials, and is integrated in important institutions such as Harvard or MIT, where the OpenCourseWare project allows access to a major part of MIT's course materials in open access [35]. In addition, universities such as the Dutch University of Utrecht are beginning to stop using the impact factor as a parameter for recruitment and promotion decisions, and their professors will be evaluated for their commitment to open science [33]. Furthermore, a study on the impact of open access on the number of citations in academic publications in civil engineering shows that papers from top-ranked journals (first quartile and second quartile) obtained more citations than non-OA articles, according to data from the WOS and Scopus databases [34]. Although it is interesting to include in the literature selection a weighting of the importance of the knowledge transmitted by the articles, no reproducible method has been found so far. Therefore, the number of citations, a widely accepted criterion, was used as a bibliometric indicator [42-44]. At this point, it is important to emphasise that this is an open access literature review that seeks to identify the most recent trends through the systematic analysis of representative publications, with proven acceptance by the scientific community, peer-reviewed, and published in recognised journals and conferences, and it does not intend in any case to be a ranking of the best publications. Finally, although there is great interest in nanomaterials based on titanium [46], aluminium [47], or magnesium [48], they were excluded from the search to avoid noise in the results, because the authors' study focuses on the macroscopic level. 
The Boolean Equation (1) indicates the search strategy. The definition of the search aims to select representative and quality literature published on magnesium, aluminium, and/or titanium light alloys, with studies of individual materials and those of hybrid or multi-material materials being of interest, whenever the materials included are lightweight structural materials. In addition, the latest trends in machining processes are explored, particularly those related to the aeronautical or automotive industries, and all this is defined under a pronounced sustainability-oriented perspective. Other inclusion criteria required for the final selection are publication in Open Access, in journals with an impact factor of Q1, Q2, or proceedings of renowned conferences, and the use of the English language.

TS $=\left(\left(\right.\right.$ aeronaut ${ }^{*}$ OR aircraft $O R$ aerosp $p^{*}$ OR air transport OR aviation OR automobile* OR vehicle OR $^{*}$ automotive*) AND (hybrid compo* OR hybrid materia* OR hybrid structur* OR multi-materia* OR multimateria* OR lightweight* OR light-weight* OR light allo* OR light materia* OR structural materia*) AND (drilling OR turning OR cutting OR machinability OR machining) AND (magnesium OR aluminium OR titanium) AND (sustainabili* OR carbon dioxide OR carbon emission* OR energy efficiency OR fossil fuel OR fuel consumption OR fuel saving OR global warming OR sustainable OR green OR energy-efficiency OR environment*) NOT (nano*))

By applying the methodology, the final selection of the 40 articles ranking the highest average number of citations per year of publication during the period 2015-2020 was reached. Finally, a literature selection with an average of 20.6 citations/article and a total of 825 citations was obtained. For the number of total citations and for the calculation of the averages per year of publication for each article, the data provided by WoS on the date of the last search on 7 December 2021 were used. An initial pre-selection and the final selection of articles were made based on the data provided by WoS at the last search. The calculation of average citations by year of publication was made, considering for each article the difference in years between the year of publication and the year 2020, both included.

Once the pre-selected articles had been reviewed and the final selection was obtained, a simple database was prepared in Excel in which the relevant information extracted from each article was stored-mainly the title, authors, scientific journal with its classification by percentile or congress, year of publication, Digital Object Identifier (DOI), and total and average number of citations per year of publication. In addition, univocal questions were defined to be asked to each article to obtain a complete picture of the interests and trends of the topics and materials investigated. Subsequently, during the review of the studies, the information extracted through closed questions was stored in the file. Table 1 shows the main characteristics and the inclusion criteria required for the selected bibliography, and Table 2 summarises the metrics of the publications where the selected studies were published.

Table 1. Selection criteria and main characteristics of aluminium, magnesium or titanium literature.

\begin{tabular}{cc}
\hline Criteria & Features \\
\hline Publication period & 6 years/2015-2020/40 articles most cited/20.6 citation per article \\
Date of last search & 7 December 2021 \\
Type of studies & Articles: Q1-Q2 scientific journals and conference proceedings \\
Search strategy & Boolean Equation (1) \\
Search engine & Web of Science (WoS) \\
Language & English \\
Type of publication & Open Access \\
\hline
\end{tabular}


Table 2. Main data associated with the quality of the scientific journals in which the selected articles were published.

\begin{tabular}{ccc}
\hline Articles Selected & $\mathbf{N}^{\circ}$ & $\%$ \\
\hline Total number & 40 & $100 \%$ \\
Proceedings Paper & 13 & $32.5 \%$ \\
Q1 & 13 & $32.5 \%$ \\
Q2 & 14 & $35 \%$ \\
\hline
\end{tabular}

\section{Literature Analysis}

Considering that a study can involve more than one material in its research, aluminium alloys are the alloys that appear in more studies, participating in 58\% of the studies, followed by titanium alloys in $43 \%$, and finally, magnesium alloys in $30 \%$. In addition, other materials used to form multi-materials also appear, such as high-strength steels [24], FRPs [25], or technical ceramics such as silicon carbide in AMMs [23]. Table 3 summarises the selected literature for this study, including the average citation by year of publication for each paper, type of publication, year of publication, country of origin based on the first author, and the topics covered.

Table 3. General summary of the literature selection, including topics covered.

\begin{tabular}{|c|c|c|c|c|c|c|c|c|c|}
\hline Ref. & $\begin{array}{l}\text { Average } \\
\text { Citation }\end{array}$ & $\begin{array}{c}\text { Publication } \\
\text { Type }\end{array}$ & Year & Machining & Fatigue & $\begin{array}{l}\text { Sustainable } \\
\text { Cooling }\end{array}$ & $\begin{array}{c}\text { Multi- } \\
\text { Material }\end{array}$ & $3 * \mathrm{AM}$ & Origin \\
\hline [49] & 45.5 & Q1 & 2019 & & & & & & China \\
\hline [50] & 27.0 & Q1 & 2020 & $X$ & & $X$ & & & China \\
\hline [21] & 24.0 & Q1 & 2020 & & & & $X$ & & Australia \\
\hline [29] & 22.8 & *PP & 2015 & & & & & $X$ & Germany \\
\hline [51] & 20.0 & Q2 & 2019 & & & & $X$ & & Italy \\
\hline [20] & 18.2 & *PP & 2016 & & & & $X$ & & $5^{*} \mathrm{SAf}$ \\
\hline [52] & 11.3 & Q1 & 2017 & & $X$ & & & $X$ & $2 * U K$ \\
\hline [53] & 11.0 & Q1 & 2017 & & $X$ & & & & China \\
\hline [19] & 9.5 & Q1 & 2015 & & & & & & $2 * U K$ \\
\hline$[54]$ & 9.0 & Q2 & 2020 & & & & & & $2 * U K$ \\
\hline [55] & 8.0 & *PP & 2018 & & & & & $X$ & Israel \\
\hline [56] & 6.6 & Q1 & 2016 & & $X$ & & & & Germany \\
\hline [57] & 6.3 & Q2 & 2018 & & & & & & $2 * U K$ \\
\hline [58] & 6.0 & Q2 & 2020 & & & & & & USA \\
\hline [28] & 4.7 & Q2 & 2018 & $X$ & & $X$ & & & Spain \\
\hline [59] & 4.0 & Q1 & 2020 & & $X$ & & & & Slovakia \\
\hline [60] & 3.7 & *PP & 2018 & & & & $X$ & $X$ & USA \\
\hline [26] & 3.3 & Q2 & 2018 & & & & & & $2 * U K$ \\
\hline [61] & 3.0 & Q̄2 & 2020 & & & & & & Spain \\
\hline [18] & 2.8 & $* \widetilde{P P}$ & 2017 & $X$ & & $X$ & & & Spain \\
\hline [27] & 2.7 & *PP & 2018 & $X$ & & $X$ & & & Malaysia \\
\hline [62] & 2.5 & Q1 & 2015 & & & & & & South Korea \\
\hline [17] & 2.3 & Q2 & 2018 & $X$ & & $X$ & $X$ & & Spain \\
\hline$[24]$ & 2.2 & $* P P$ & 2016 & & & & $X$ & & Germany \\
\hline [22] & 2.0 & Q2 & 2017 & & & & $X$ & & Germany \\
\hline [25] & 2.0 & *PP & 2017 & $X$ & & & $X$ & & Italy \\
\hline [63] & 2.0 & *PP & 2017 & & & & & & Malaysia \\
\hline [64] & 2.0 & Q1 & 2016 & $X$ & & $X$ & & & India \\
\hline [65] & 2.0 & Q2 & 2019 & & $X$ & & & & Spain \\
\hline [66] & 2.0 & Q2 & 2020 & & $X$ & & & & Spain \\
\hline [31] & 2.0 & Q1 & 2020 & & & & & & France \\
\hline [23] & 1.8 & Q1 & 2017 & $X$ & & & $X$ & & Spain \\
\hline [23] & 1.7 & Q2 & 2018 & $X$ & & $x$ & $X$ & & Spain \\
\hline [67] & 1.7 & Q1 & 2015 & & $X$ & & & & $4^{*} \mathrm{SA}$ \\
\hline [68] & 1.3 & *PP & 2017 & $X$ & & & & & USA \\
\hline [69] & 0.8 & Q2 & 2015 & & & & $X$ & & Poland \\
\hline [70] & 0.8 & *PP & 2017 & & & & & & Spain \\
\hline [71] & 0.7 & Q2 & 2018 & $X$ & & $X$ & & & Spain \\
\hline [30] & 0.7 & *PP & 2015 & & & & & & Germany \\
\hline [71] & 0.7 & Q1 & 2018 & & & & & & Spain \\
\hline [72] & 0.3 & $* P P$ & 2018 & $X$ & & & & $X$ & $5 *$ SAf \\
\hline
\end{tabular}

*PP Proceedings paper; $2 *$ UK United Kingdom; $3^{*}$ AM Additive Manufacturing; $4 *$ SA Saudi Arabia; $5 *$ SAf South Africa. 


\subsection{Machining and Sustainable Cooling/Lubrication}

$40 \%$ of the selected studies involve a machining process in their research, with turning being the most analysed process with $38 \%$, followed by drilling with $31 \%$ of the machining studies. The costs of lubricants, coolants, and cutting fluids (CFs) are estimated at $17 \%$ of total machining costs, and cutting tool costs at $4 \%$. Cutting fluids contain harmful chemicals to the environment and can cause worker illnesses such as respiratory problems, asthma, and cancer [28]. Therefore, 75\% of the selected machining articles focus their research on the analysis of sustainable cooling/lubrication techniques, with dry machining appearing in 65\% [16-18,28,50,71], and cryogenic cooling [29,30,51] and Minimum Quantity Lubrication (MQL) $[18,29,30]$ in $18 \%$ of the machining studies. There are also research lines oriented to develop processes utilising sustainable cutting or machining fluids based on vegetable oils such as sesame, coconut, sunflower, palm, and others [28,64].

In 2018, Garcia-Martinez et al. [28] conducted an analysis of the literature published since 2015 on non-traditional lubrication techniques applied to turning, drilling, and milling processes. The study analyses MQL, cryogenic lubrication, minimum quantity cooling lubrication (MQCL), high-pressure cooling (HPC), and laser-beam-assisted machining (LBM) processes. Although dry machining is also considered a sustainable solution, the authors did not include it in the review because of the difficulty of using this process in machining titanium alloys due to their low thermal conductivity, low elastic modulus, and high chemical affinity with machining tool insert materials. The study concludes that cryogenic lubrication improves the surface quality of the machined parts, so this technology is considered to have the potential to replace traditional flood lubrication. However, the conclusions on tool wear are not so clear since, although in some works an improvement in tool life is reported, in others, more significant wear appears due to the increase in Ti hardness at low temperatures. Therefore, MQL seems, for many of the authors, as a good compromise solution that reduces the amount of coolant and achieves the same or better surface roughness results than conventional cooling. Another innovative technology analysed is laser-beam-assisted machining (LAM), which aims to preheat the part and facilitate cutting. However, it is currently difficult to correctly control the process parameters, resulting in rapid tool wear. The most commonly used response variables in studies to develop sustainable cooling lubrication technologies are cutting forces, surface roughness, and tool wear.

Cryogenic cooling is often suggested to solve problems associated with titanium machining, mainly affecting tool life, and caused by its low thermal conductivity and high chemical affinity. However, one of its drawbacks is the difficulty in machining parts exposed to the extremely low temperatures of cryogenic machining, producing a hardening of the workpiece and a subsequent increase in cutting forces. In 2018, Suhaimi et al. [27] proposed a new tool design that allows for the cooling of the tool by an internal circuit through cryogenic cooling, and keeps the part machined at standard working temperature to avoid hardening. The design integrates an internal cooling circuit in the tool that utilises nitrogen as a cryogenic fluid. The performance of indirect cryogenic cooling was compared with good results of those obtained by other cooling technologies: flood cooling, MQL, and the conventional cryogenic cooling method.

In 2020, Gupta et al. also carried out a comparative study of the trendiest sustainable cooling systems for difficult-to-machine materials: dry machining, cryogenic cooling, and the combination of cryogenic cooling with MQL. Their efficiency is analysed through several parameters; temperature, thrust force, surface roughness, and tool wear. The hybrid process provides cooling for the workpiece and the tool, and at the same time, lubricates the cutting zone, protecting the machine from vibration and wear. The research team concludes that the hybrid liquid nitrogen (LN2) + MQL coolant produces the best results of the three types of environmentally friendly coolant compared, reducing total machining costs by up to $65.84 \%$, energy consumption by $15.89 \%$, carbon emissions, cutting force values, surface roughness, and cutting temperature $[50,73]$. Figure 2 shows the different 
sustainable machining technologies in the form of a ring graph: dry machining, MQL, cryogenic, high-pressure coolants, and biodegradable oils.

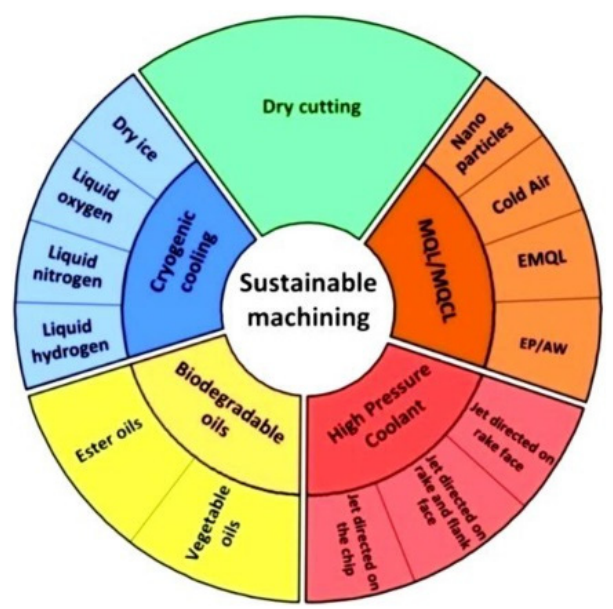

Figure 2. Ring of sustainable machining, reproduced from [50,73], with permission from Elsevier, 2020 and 2019.

Concerning the machining processes of single materials contained in the selection, they are diverse, including articles on drilling [18], turning [71], milling [68], electro discharge machining (EDM) [64], or abrasive water jet cutting (AWJC) [23].

In the drilling process, drill manufacturers do not usually define the best process conditions for all possible materials to be machined; this is the case for magnesium alloys. For this reason, and as the first step in a more extensive and in-depth study on the machining of magnesium alloys, Berzosa et al. [18] researched which tool shows the best conditions for machining magnesium parts and is compatible with the stringent tolerances required for machining in the aeronautical industry. In this study, a Design of Experiments (DoE) test was initially designed following Taguchi guidelines. The factors identified as potentially influential were the drill bit tip angle, cutting speed, feed rate, and type of cooling. The values obtained were analysed using the analysis of variance method (ANOVA), and a roughness prediction model was developed, although the correlation of the regression indicated the existence of influential parameters not included in the model. The conclusions revealed cutting speed as the most significant factor. For high cutting speeds, better Ra results were obtained for $118^{\circ}$ drills, while for low cutting speeds, better results were obtained for $135^{\circ}$ drills.

As for the turning process in single materials, macro-geometric deviations are essential for the function and reliability of the aeronautical parts. In this sense, in 2019 and 2020 Martín Béjar et al. $[65,66]$ studied the turning parameters' influence over parallelism, straightness, eccentricity, roundness, concentricity, and cylindricity in high-slenderness components. They compared the results with the previous test performed with more rigid pieces, concluding that feed rate is the parameter with more influence on most of the deviations, while the cutting speed has less influence. The parts with greater rigidity showed less sensitivity to the test with different cutting parameters. Previously, in 2018, Gomez-Parra et al. [71] had analysed the influence of corrosion on turning processes in aluminium alloys. In the study, the effect of the machining on the ultimate tensile strength (UTS) of specimens subjected to marine corrosion was analysed. The study indicated that machining improves the tensile strength of the samples, as machining generates residual compressive forces responsible for the improvement. Furthermore, it was observed that the higher the residual compressive force generated, the higher the UTS, and in addition, the UTS increases with increasing feed rate. These results are consistent with those presented in 2017 by Bermudo et al. [70] in a comparable test on a dry-turned aluminium alloy. 
Mitchell et al. in 2020 [58] also carried out a study on corrosion, but in this case, analysing the influence of roughness on corrosion in magnesium alloys in marine environments. The researchers concluded that corrosion is a significant parameter, and that corrosion increases with the roughness of the part in magnesium alloys.

On the other hand, in the search to lighten the mass of the structures, lightweight and resistant designs are sometimes designed, but they complicate the machining processes. This is the case with the aluminium sandwich panel with a honeycomb structure, a structure widely used in aerospace and aeronautical components thanks to its lightness and high strength. This type of panel consists of two outer aluminium sheets and an inner aluminium core in the form of a honeycomb. This distribution provides high strength, but it is difficult to machine due to the variable cutting conditions in the core, so machining often requires significant post-processing. In 2017, Yip-Hoy et al. [68] performed an experimental milling test with this type of sandwich panel, aiming to better understand this type of machining and optimise the process. The results showed the difficulty of the process, concluding the existence of high vibrations in the first part of the machining on the top sheet and the upper area of the honeycomb structure, and pointing out the need for further tests to optimise this process.

On the other hand, there is also a research line that promotes sustainable cutting fluids based on biodegradable vegetable oils such as sesame oil, coconut oil, sunflower oil, palm oil, etc. In 2016, Singaravel et al. published a study [64] on vegetable oil-based dielectric fluids in EDM machining and compared the surface roughness results with those obtained using conventional dielectric fluids. For this purpose, the authors performed machining tests on $\mathrm{Ti}_{6} \mathrm{Al}_{4} \mathrm{~V}$ specimens and used sunflower, colza, and jatropha oils as biodegradable dielectric fluids, and paraffin as a conventional dielectric fluid for comparison. The study concluded that sustainable biodegradable oils can be successfully used. They have similar dielectric properties and erosion mechanisms to conventional dielectric fluids, making them a good option for sustainable manufacturing. Table 4 presents a summary of the five most cited selected articles on machining and sustainable cooling technologies, including the average number of citations per year of publication, type of publication, year of publication, material machined, machining process involved, type of cryogenic cooling involved, and country of origin of publication based on the nationality of the first researcher.

Table 4. Top 5 articles on sustainable machining and cooling processes.

\begin{tabular}{cccccccc}
\hline Ref. & $\begin{array}{c}\text { Average } \\
\text { Citation }\end{array}$ & $\begin{array}{c}\text { Publication } \\
\text { Type }\end{array}$ & Year & Material(s) & Process & Key Topics \\
\hline$[50]$ & 27.0 & $\mathrm{Q} 1$ & 2020 & $\mathrm{Ti}$ & Turning & Cryogenic/Dry & China \\
{$[28]$} & 4.7 & $\mathrm{Q} 2$ & 2018 & $\mathrm{Ti}$ & $3^{*} \mathrm{SoA}$ & Cryogenic/Dry $/ 4^{*} \mathrm{MQL}$ & Spain \\
{$[61]$} & 3.0 & $\mathrm{Q} 2$ & 2020 & $\mathrm{Mg} / \mathrm{Ti} / \mathrm{Mg}$ & Drilling & Dry & Spain \\
{$[18]$} & 2.8 & $5^{*} \mathrm{PP}$ & 2017 & $\mathrm{Mg}$ & Drilling & Dry/4*MQL & Spain \\
{$[64]$} & 2.7 & $\mathrm{Q} 1$ & 2018 & $\mathrm{Ti}$ & ${ }^{*} \mathrm{EDM}$ & Biodegradable oil & India \\
\hline
\end{tabular}

*EDM Electrical discharge machining; $2 *$ AWJM Abrasive water jet cutting; $3 *$ SoA State of art; $4 *$ MQL Minimum quantity lubrication; $5^{*} \mathrm{PP}$ Proceedings paper.

\subsection{Multi-Materials}

Another topic with a marked trend is the study of multi-material components, found in $33 \%$ of the selected studies. As important sub-topics, the joining of dissimilar materials with $46 \%$, and the machining of multi-material compounds with $38 \%$ of the studies dedicated to multi-materials, are worth highlighting. In addition, the multi-material combination participating in most studies is the metal-metal combination, included in $62 \%$ of the papers that include multi-materials, followed by AMMs, present in 31\%. The automotive industry has long been trying to implement new ways to reduce the weight of car bodies. It is becoming increasingly common to find car bodies made of multi-materials consisting of aluminium and steel joined together. Currently, the mechanical performance of multimaterial joining is limited, and it is often necessary to develop or adapt technologies that 
were not previously used in the automotive sector. For this reason, in 2019 Gullino et al. [51] carried out a state-of-the-art review of the available welding technologies for joining dissimilar materials, based both on the fusion of base materials and on solid-joining technologies, focusing the analysis on technologies applicable to the joining of steels and wrought aluminium alloys. Among the fusion technologies, the review includes: resistance spot welding (RWS), in which a hybrid process combines resistance spot welding and adhesive joining to seal and prevent corrosion, and laser beam welding (LBW), in which laser technology is used to create a weld joint that minimises the heat-affected zone. Arc Welding is a conventional welding process that uses electricity to melt the metal and join the materials together. In principle, this technology is less effective than laser welding because it provides more heat and produces a negative intermetallic layer at the joint between the aluminium and steel.

Regarding solid-joining technologies, the following technologies are included: explosion welding and transition joints (EWTS), in which an explosion is applied, there is no external heating, and welding is achieved mainly due to high collision velocity; magnetic pulse welding (MPW), which is a similar method to the previous one but where the material is accelerated by a magnetic field; roll bonding (RB), a technique that uses high pressures to fabricate a bimetallic sheet; friction stir welding (FSW), a process that utilises a rotating tool to generate frictional heat and plastic deformation, and where welding is achieved by a combination of heat and pressure; friction bit joining (FBJ), a process that uses a consumable drill bit as a joining material between aluminium and sheet steel in the automotive industry; and ultrasonic spot welding (USW), a process that relies on a translational movement between metal sheets, creating local deformation and generating sufficient heat for joining. Figure 3a shows an example of a steel-titanium-aluminium hybrid composite formed by blast welding in 2019 [51].

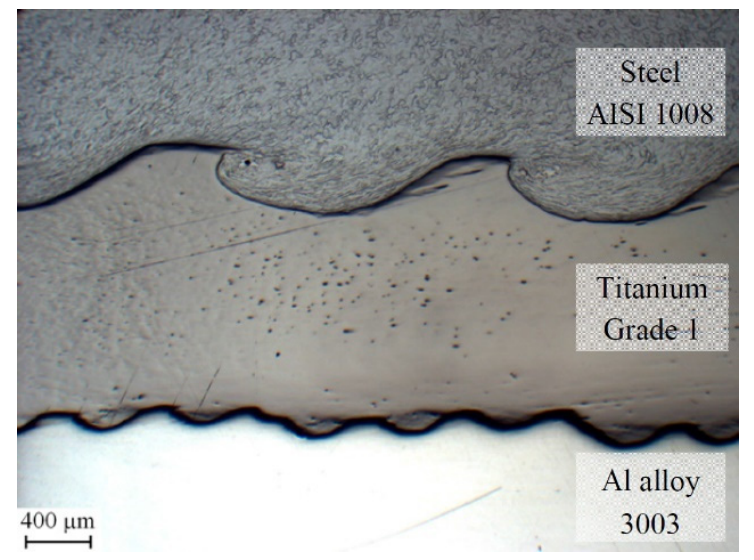

(a)

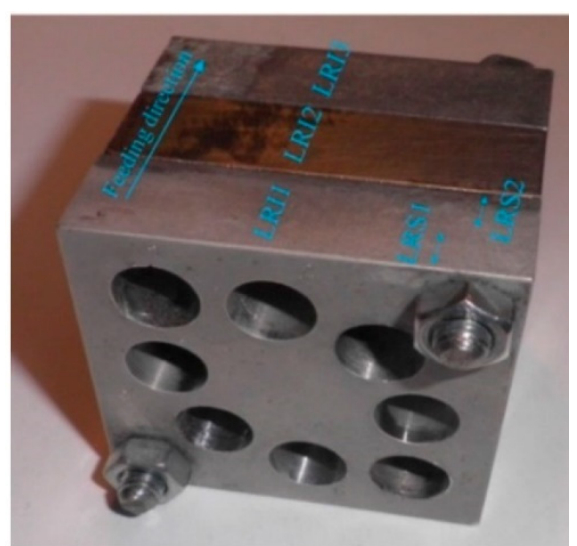

(b)

Figure 3. (a). Cross-section of an explosion-welded joint between a steel and an aluminium alloy with a titanium interlayer [51]; (b) Cutting Parameter Selection for Efficient and Sustainable Repair of Holes Made in Hybrid Mg-Ti-Mg Component Stacks by Dry Drilling Operations [16].

Lahdo et al. [24] also conducted a study aimed at the optimisation of laser welding applied to the joining of aluminium and high-strength steel parts. The study was addressed to the maritime transport sector, in which the reduction of consumption and pollutant emissions by the decrease in mass is also a primary objective. The quality of the welded joint depended on the intermetallic phases formed, and joints with a tensile strength of $10 \mathrm{kN}$ were achieved in the experimental test. From the analysis of the test data, it was stated that laser weld penetration and width increase with the increase in energy per unit length, and that weld bead width has a significant influence on the shear strength. The failures found in the test specimens studied were mainly located in the weld metal of the steel zone. 
FSW welding is a solid-state process that uses a lower temperature compared to fusion welding processes. This makes FSW an excellent candidate to use for joining materials of a dissimilar nature, as it avoids the formation of intermetallic compounds. Particularly for magnesium and aluminium joining, both are materials of high potential for the aeronautical and automotive industries, so the study of reliable joining is essential in developing their combined use. Baghdadi et al. [63] conducted an experimental test in 2017 to investigate the properties of the FSW weld joint between aluminium and magnesium alloys, and examine the effect of tool offset on the strength of the joint (see Figure 4). In the study, the authors referred to welding efficiency as the ratio between the tensile strength of welded specimens in the investigation and the UTS of the magnesium alloy. The efficiency achieved by the welding varied from $29 \%$ to $68 \%$. Finally, it was concluded that the rotational speed and offset of the tool significantly influence the resulting UTS.
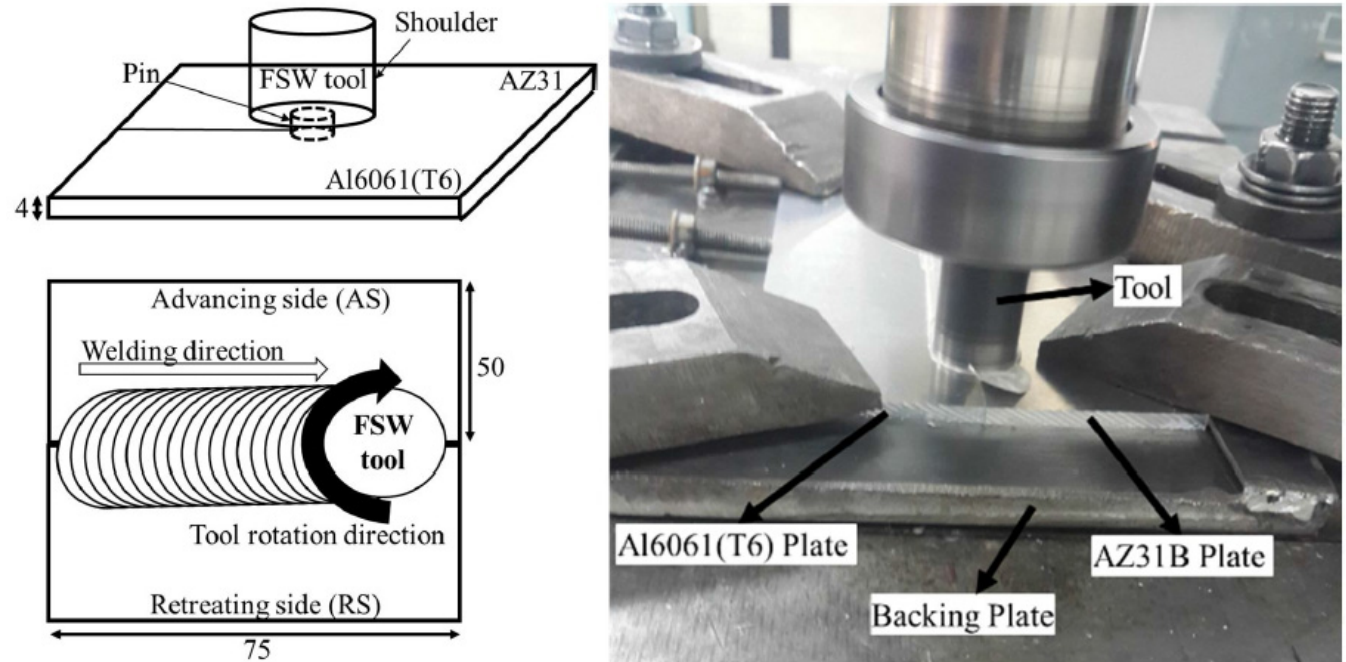

Figure 4. Joint design and dimensions (millimetre) [64].

Another type of joint frequently used in the automotive and aeronautical industries is a mechanical joint using screws or rivets; for that purpose, the machining of the parts is critical, and in the case of multi-material parts, the availability of machining processes adapted to multi-material combinations allows for the optimisation of time and cost of manufacture and repair.

Spot welding is another of the most commonly used methods for joining aluminium and steel parts in the automotive industry. For this reason, Nikolic et al. [59] carried out an experimental analysis of the influential parameters on the lifetime of components joined using this technology, concluding that the lifetime at fatigue of the welded joint increases with the increase in the thickness of any of the individual plates, with the increase in the diameter of the welding point, and decreases with the increase of the applied load. In addition, the crack propagation behaviour was analysed, and it was concluded that the crack practically does not propagate until the number of load cycles reaches 30,000, at which point the crack length starts to increase linearly up to about 40,000 cycles, after which the crack growth becomes unstable. The lifetime is always longer in mono-material composites, as there are no additional residual stresses and they have the same coefficient of expansion. Continuing the theme of fatigue life of alloys, especially in the region of very high cycle fatigue (VHCF), in 2016 Heinz et al. [56] performed very high cycle fatigue tests (VHCF) using $20 \mathrm{kHz}$ ultrasound on titanium alloy specimens, finding a significant decrease of the tolerable stress amplitude and a change of the failure type from surface to subsurface at more than $10^{7}$ cycles. In addition, SEM analyses showed irreversible microstructural changes and subsurface volume defects in the samples tested up to $10^{10}$ cycles (grain refinement, twinning, and microcracking). Moreover, Yang et al. in 2017 analysed the effect of stress ratio on the very high cycle fatigue behaviour of a titanium turbine blade alloy by 
ultrasonic fatigue experiments. Based on fracture mechanics, the fatigue failure process was divided into four stages: crack initiation, slow propagation, fast propagation, and final fatigue failure, where less than $3 \%$ of the total fatigue life was in the initiation stage, and more than $95 \%$ belonged to the crack growth stage [53].

On the other hand, the bores drilled in aircraft components to assemble the different parts are exposed as well to cyclic stresses, leading to fatigue failures. Furthermore, given the responsibility of the pieces, they must be checked frequently for maintenance and repair of possible cracks that could cause a catastrophic part failure in service. For this reason, Rubio et al. [16] in 2018 carried out a study of the optimum drilling process parameters of multi-materials formed by magnesium and titanium by dry machining. Figure $3 \mathrm{~b}$ presents the multi-material specimen designed for the test. Magnesium presents an ignition temperature below its melting temperature that makes it easily ignitable, and titanium possesses a low thermal conductivity and high reactivity that tends to produce cracks in the cutting tools. Another added difficulty was that the operation was carried out in a single step, drilling materials of a dissimilar nature in a single step, which required compromise parameters intermediate to those that are ideal for each material. The study conducted a DoE following the Taguchi method. The parameters of potential influence were defined as feed rate, cutting speed, bit layer, positioning of the plate relative to the stacked composite, and position of the measurement relative to the plate. An ANOVA was used to examine the results. The study concluded that the most influential factor is the plate position regarding the stack. The research concluded that dry redrilling repair operations can be carried out successfully and within the standard tolerances required for machining in the aeronautical sector. In 2018, Rubio et al. [17] complemented this work with an experimental turning test on a multi-material made up of magnesium and aluminium alloys. In this case, the surface quality obtained after machining was strongly influenced by the feed rate, and low values were the most advantageous to achieve low roughness. Furthermore, different combinations of cutting parameters were identified that efficiently perform these operations, optimising the machining times and the surface quality obtained. As part of the same study, in 2020, Blanco et al. [61] carried out a comparative re-drilling test on magnesium-based multi-material components for the repair of aeronautical parts by re-drilling. The study concluded the existence of a directional effect dependent on the cooling/lubrication employed and the type of multi-material composite.

Regarding innovative trends, it is also interesting to mention a proposal for integrating sensors in lightweight structures to obtain smart structures that provide information about their status [22], or the integration of new technologies in production lines, such as collaborative robots, to optimise the process. With this in mind, in 2017, Cirillo et al. [25] proposed the use of collaborative robots (COBOTs) to make the drilling process more efficient and reduce the number of human operations that do not add value. Drilling is one of the most frequent and critical operations. It is currently performed by experienced operators to minimise potential defects, especially in high-value-added components such as CFRP and aluminium or titanium multi-materials in the aeronautical sector. A critical point in the process is to achieve the tolerances that allow a correct final assembly. The aeronautical industry needs to drill thousands of holes per aircraft. For this reason, the parts of different materials that make up multi-materials are often placed in their relative assembly position, and the drilling is carried out in a single operation. This procedure saves time and also allows for perfect alignment and relative positioning of the holes. The proposed process performs the multi-material drilling operation in a single step and uses low-cost standard robots and off-the-shelf components to minimise the cost of deployment. Furthermore, it is designed to be user-friendly for operators familiar with the drilling process, but not with the programming and control of robotic systems. 
On the other hand, primary aluminium has a high environmental impact caused by its high energy consumption, $\mathrm{CO}_{2}$ emissions, and waste generation compared to secondary aluminium processing. While it is true that aluminium is a material with good recyclability, the growth of aluminium multi-materials and the joining of dissimilar materials makes it increasingly challenging to obtain high-purity recycled aluminium. In 2020, Soo et al. [21] carried out an experimental trial in a large recycling facility in Belgium. The goal was to evaluate several joining techniques of multi-material parts on the quality of the recycled material. The paper concluded that the joints that most affect the quality are the mechanical joints such as bolts and rivets.

An interesting case is that of the aluminium metal matrix composites reported in $36.1 \%$ of the multi-material studies. AMMs have an excellent mass/strength ratio, good ductility, high strength and elastic modulus, low coefficient of expansion, excellent wear and corrosion resistance, high creep temperature, and good fatigue behaviour. For these reasons, AMMs are used in the automotive and aerospace industries in applications such as robots, high-speed machinery, high-speed rotating shafts, automotive engines, and brake parts. The ceramic particles must be homogeneously distributed within the metal matrix to reinforce the structure. The degree of reinforcement depends on the amount, distribution, and size and shape of particles. The most commonly used particles in aeronautical structural applications are $\mathrm{SiC}$ and $\mathrm{B} 4 \mathrm{C}$ [20].

In addition, parts manufactured by the casting process have a complex structure, and in the case of AMMs include a strong reinforcement phase dispersed in the lightweight metal matrix. The properties of the compound material are determined by the homogeneity of the reinforcement phase, i.e., its distribution, quantity, size and shape, and porosity. Detecting defects at an early stage is essential to avoid problems arising from the use of defective structures, and for this reason, quality controls are carried out continuously. The technologies currently used for early defect detection are non-destructive testing such as computerised tomography, X-ray diffraction, or acoustic emission. However, there are also studies for the development of new detection systems, such as using the coherence function to verify the internal structure in cast composites [69].

In 2015, Hassan et al. reported an interesting test of a sintered magnesium-nickel multi-material. In the experiment, a good dispersion of the nickel reinforcements in the magnesium matrix was obtained, and the hardness and tensile strength of the multi-material were significantly improved without affecting the yield strength. However, the ductility deteriorated and the fracture mode changed from pseudo-ductile to brittle, conditioned by the reinforcement particle when the multi-material was under tensile loading [67].

On the other hand, conventional machining of AMM is very complex due to the extremely abrasive conditions of the material leading to short tool lifetimes. For this reason, Ares et al. conducted a study in 2017 on the use of abrasive water jet cutting (AWJM) technology in the machining of Al-SiC. In the study, an experimental test was carried out using the AWJM process, and the parameters with the greatest influence on the machining surface quality and on the taper angle obtained from the machining process were investigated. The analysis of the data obtained was performed using an ANOVA, and it concluded that it is more advantageous to employ low feed rates, medium-high pressure levels, and intermediate abrasion rates for the AWJM to obtain a good compromise between the results of surface roughness and taper angle [23]. presents a summary of the five most cited selected articles on multi-materials or hybrid components, including the average number of citations per year of publication, type of publication, year of publication, the multi-material investigated, the process investigated, the main topic, and the origin of the publication considering the nationality of the first researcher. Table 5 presents a summary of the five most cited selected articles on multi-materials or hybrid components, including the average number of citations per year of publication, type of publication, year of publication, multimaterial, main topic, and country of origin of publication based on the nationality of the first researcher. 
Table 5. Top 5 articles on multi-materials or hybrid components.

\begin{tabular}{|c|c|c|c|c|c|c|}
\hline Ref. & $\begin{array}{l}\text { Average } \\
\text { Citation }\end{array}$ & $\begin{array}{c}\text { Publication } \\
\text { Type }\end{array}$ & Year & Material(s) & Process & Origin \\
\hline [21] & 24.0 & Q1 & 2020 & $\mathrm{Al} / \mathrm{St}$ & Recycling & Australia \\
\hline [51] & 20.0 & Q2 & 2019 & $\mathrm{Al} / \mathrm{St}$ & Welding & Italy \\
\hline [20] & 18.2 & $5 * \mathrm{PP}$ & 2016 & ${ }^{*} \mathrm{AMMs}$ & $2 *$ SoA & South Africa \\
\hline [59] & 4.0 & Q1 & 2020 & $\mathrm{Al} / \mathrm{St}$ & Welding & Slovakia \\
\hline [60] & 3.7 & $5 * \mathrm{PP}$ & 2018 & $\mathrm{Al} / \mathrm{Mg} / \mathrm{Ti}$ & ${ }^{3 *} \mathrm{AM}$ & USA \\
\hline
\end{tabular}

${ }^{*}$ AMMs Aluminium metal matrix; ${ }^{2 *}$ SoA State of Art; ${ }^{3 *}$ AM Additive manufacturing; ${ }^{4 *}$ JDM Joining dissimilar materials; ${ }^{5 *}$ PP Proceedings paper.

\subsection{Additive Manufacturing}

Additive manufacturing is a topic of increasing interest and appears in $18 \%$ of the selected studies. Additive manufacturing refers to manufacturing processes in which parts are built layer-by-layer directly from a 3D model.

The use of an additive manufacturing process reduces waste materials and manufacturing times, increases added value by obtaining parts with a shape close to the final form [52], and allows for the production of much more complex shapes and interior cavities such as cooling circuits [54], therefore optimising manufacturing times, the ratio of final material to initial material used, the mechanical strength of the component, functionalities, and the energy used in the forming process of the piece. However, the technology currently has associated disadvantages to solve such as porosity, anisotropy, or low fatigue strength $[55,60]$ that limit its use, especially in critical parts, so many studies focus now on the development of different additive manufacturing technologies.

In 2018, Dimitrov et al. [72] compared relevant manufacturing techniques applicable to the manufacture of titanium parts. The study aimed to increase knowledge about titanium processing so that South Africa can move from being a supplier to participating in the entire value chain of the material, especially in the higher value-added stages. Machining of titanium parts is complex. The material is considered challenging and time-consuming to machine; for example, it is ten times slower than machining aluminium, so the study aims for near net shape manufacturing. Based on this study, powder metallurgy (PM) shows from 2000 parts per year higher economic efficiency than metal injection moulding (MIM), additive manufacturing (AM), and traditional machining, and the price is strongly influenced by the cost and quality of the titanium powder. MIM suits complex-shaped parts of more than 10,000 units per year and smaller than $5 \mathrm{~cm}$ in size. Additive manufacturing (AM) focuses on individual pieces with complex shapes. On the other hand, forging has a lower material loss compared to machining, and increased strength, but it has the disadvantage of lower-dimensional accuracy. The single point incremental forming (SPIF) process is mainly used for rapid prototyping and biomedical products, but its geometric accuracy is poor, and its residual stress is high. The most commonly used response variables in titanium studies are surface roughness and residual stress condition. Machining with a better finish produces a higher compressive residual stress, which can be positive in terms of fatigue. The study includes a practical case- the manufacturing comparison of a blade through different processes: complete machining, pre-form plus machining, and additive manufacturing plus machining. The analysis of the experimental test concluded that the machining process provides excellent flexibility, but has a low material usage ratio, so it is only recommended in the case of small production batches. Combining forming and machining reduces the price by increasing the number of units produced and has a low flexibility and tool life, so it only suits medium-high demands. Finally, additive manufacturing offers high flexibility and good material usage, but the disadvantages are high residual stress and the high cost of titanium powder. 
On the other hand, one of the most researched techniques is selective laser melting (SLM), a laser additive manufacturing technology that uses lasers to synthesise raw material powder and allows topologically optimising designs for aeronautical and aerospace structural applications. Uhlmann et al. [29] conducted a study in 2015 on the characteristics and mechanical properties of titanium parts manufactured using SLM. The analysis included a comparative analysis regarding parts manufactured by casting, including density, micro-hardness, surface roughness, strength, and fatigue behaviour. The layer thickness significantly influenced the final result, so the study set a layer thickness of 50 microns. The obtained pieces were post-treated by heat treatment and hot isostatic pressing (HIP), which increased the surface quality, closing the micro-cracks and reducing the surface stresses. In the post-test of the samples, a relative density of $98.15 \%$ and a micro-hardness of $89 \%$, related to the literature average density, were obtained. Computed tomography analysis revealed a porosity in samples without HIP post-treatment of 3.05\% (relative density of $96.95 \%$ ), and with post-treatment of $0.81 \%$ (relative density of $99.15 \%$ ), with a pore volume reduction of more than $160 \%$. The Rz roughness was maintained in the range of 103-150 microns [29].

Another of the most studied technologies is wire arc additive manufacturing (WAAM), which employs a fusion welding electrode [52]. The process has many difficulties in achieving the required mechanical properties and dimensional tolerances because of the difficulty in controlling and tracking the process. For this reason, $\mathrm{Xu}$ et al. [57] developed a prototype sensor in 2018 that obtains an accurate voltage and current signal. The equipment monitors current/voltage, workpiece surface, and ambient oxygen level during the additive process, improving the quality obtained. Another lesser-known additive technology that enables the repair of multi-material parts is cold spray (CS) technology. In 2018, Widener et al. [60] showed the potential of using this technology to repair pieces to promote the reuse of components, rather than manufacture new parts after wearing. CS technology is a type of additive manufacturing that uses kinetic energy rather than thermal energy to create a coating on a wide range of base materials. The coating is created by spraying metal powders at supersonic speeds of Mach 1-3. The low gas temperature at the nozzle exit compared to melt technologies, between 100 and $400{ }^{\circ} \mathrm{C}$, results in low substrate heating. Low temperatures and short durations reduce the risk of grain growth, and phase transformation and the heat-affected zone (HAZ) are minimal. On the other hand, although additive manufacturing is one of the trendiest processes today, the process is still far from being fully developed. One of the most relevant problems that researchers face is residual porosity, which affects the mechanical properties and fatigue strength of parts manufactured by additive manufacturing. In 2018, Popov et al. [55] investigated the efficiency of HIP post-treatment to decrease the porosity of Ti components fabricated by additive manufacturing using electron-beam melting (EBM). This treatment applies simultaneously high pressure and high temperature in an inert gas atmosphere. The study examined the microstructure and fatigue strength of EBM-fabricated and HIP-treated specimens, and the results clearly demonstrated an enhancement of the mechanical properties where the HIP process was applied, clearly improving the fatigue strength, as can be seen in Figure 5. In untreated parts, cracks initiate more frequently in surface defects, whereas, in treated parts, crack initiation is usually in the interior of the part volume. Table 6 presents a summary of the five most cited selected articles on additive manufacturing, including average number of citations per year of publication, type of publication, year of publication, material used, additive manufacturing process included, the main topic, and origin of the publication based on the nationality of the first researcher. 


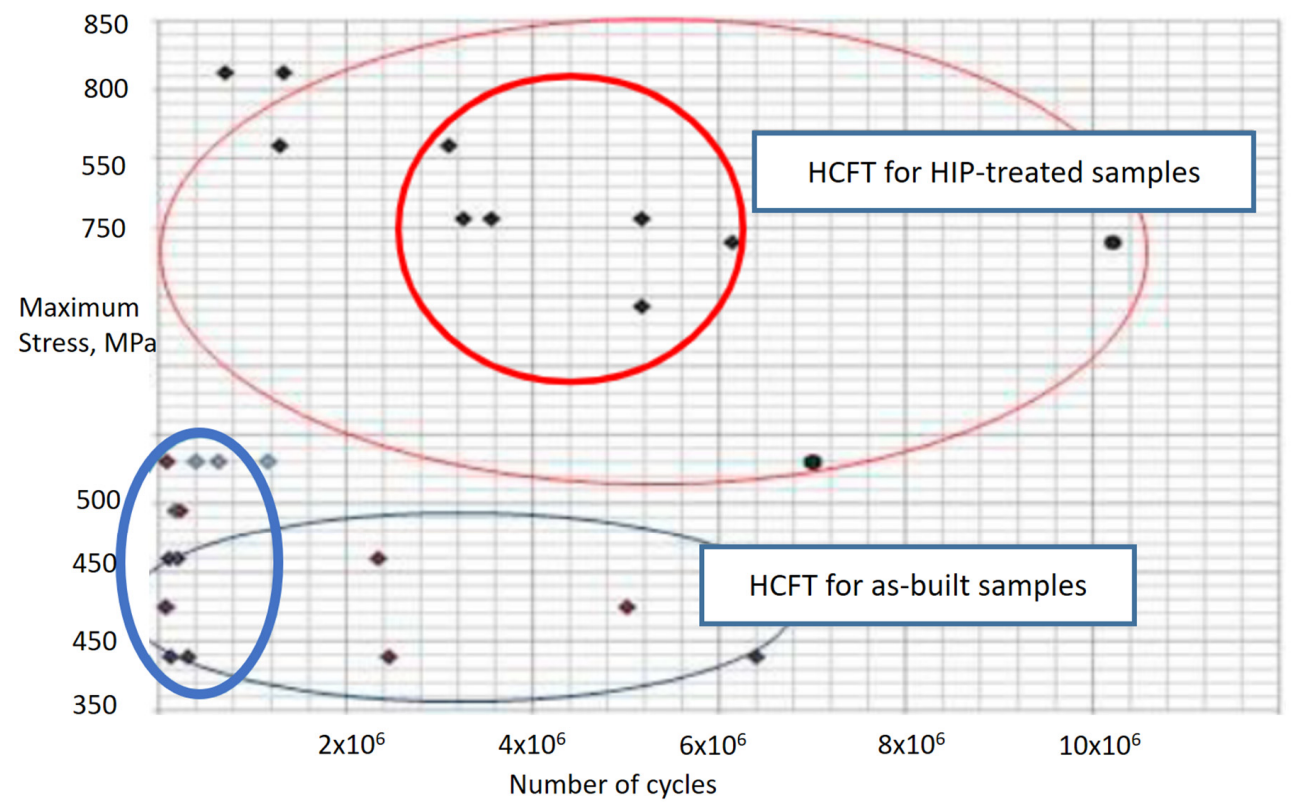

Figure 5. High-cycle fatigue test results obtained on specimens before and after HIP treatment, reproduced from [56], with permission from Elsevier, 2021.

Table 6. Top 5 articles on additive manufacturing.

\begin{tabular}{cccccccc}
\hline Ref. & $\begin{array}{c}\text { Average } \\
\text { Citation }\end{array}$ & $\begin{array}{c}\text { Publication } \\
\text { Type }\end{array}$ & Year & Material(s) & Process & Key Topics & Origin \\
\hline$[29]$ & 22.8 & $5 * \mathrm{PP}$ & 2015 & $\mathrm{Ti}$ & ${ }^{2 * \mathrm{SLM}}$ & $3 * \mathrm{HIP}$ & Germany \\
{$[52]$} & 11.3 & $\mathrm{Q} 1$ & 2017 & $\mathrm{Al} / \mathrm{Ti} / \mathrm{St}$ & $4 *$ WAAM & Process design & United Kingdom \\
{$[54]$} & 9.0 & $\mathrm{Q} 2$ & 2020 & $\mathrm{Al} / \mathrm{Ti} / \mathrm{St}$ & $2 * \mathrm{SLM}$ & Tools & United Kingdom \\
{$[71]$} & 8.0 & $5 * \mathrm{PP}$ & 2018 & $\mathrm{Ti}$ & $5 * \mathrm{EBM}$ & $3 * \mathrm{HIP}$ & Israel \\
{$[57]$} & 6.3 & $\mathrm{Q} 2$ & 2018 & $\mathrm{Ti}$ & $4 *$ WAAM & Monitoring & United Kingdom \\
\hline
\end{tabular}

${ }^{*}$ TC Technology comparison; ${ }^{2 *}$ SLM Selective laser melting; ${ }^{3 *} \mathrm{HIP}$ hot isostatic pressure treatment; ${ }^{4 *}$ WAAM Wire Arc Additive Manufacturing; ${ }^{5 *} \mathrm{EBM}$ Electron beam melting; ${ }^{5 *} \mathrm{PP}$ Proceedings paper.

\section{Conclusions}

Transport-related industries, such as aeronautics and the automotive industry, have established the reduction of consumption and pollutant emissions as a top priority, pushed by increasingly restrictive environmental legislation and a society that is more demanding and aware of the need for sustainability. In this context, one line of work is the replacement of conventional structural materials with lightweight materials that meet the stringent requirements demanded and, at the same time, contribute to reducing the consumption of vehicles and aircraft. Among these materials are metallic alloys of aluminium, titanium, and magnesium, which have excellent weight-to-strength ratios and can be used individually, in combination with one another or with other lightweight structural elements. For this reason, the authors considered it interesting to carry out a state-of-the-art review on these materials to know the trend on materials studied, combinations used, current sustainable processes applied, and machining processes and sustainable cooling/lubrication involved.

In addition, a methodology adapted from the PRISMA statement was established. The aim is to minimise potential biases in the selection and analysis of the literature. This methodology ensures the availability of relevant and representative articles, with contrasted quality, and clear and homogeneous inclusion criteria.

The main criteria chosen were publications in Open Access, in English, using Web of Science as the search engine. As a bibliometric indicator for the selection, the average number of citations per year of publication was adopted. In addition, the search was carried out using predefined Boolean equations based on keywords. The criteria aim to 
review the open-access literature to identify the most recent trends by using representative publications, with proven acceptance by the scientific community, that are peer-reviewed, and are published in recognised journals and conferences. It is important to emphasise that the purpose is not to make a ranking of the best publications but to study the trend. As a next step, a future review employing similar criteria, but including both Open Access and non-Open Access, is considered to be of interest, in order to analyse differences and deepen the study. The final selection consists of the 40 most cited related research papers during the period 2015-2020, with an average of 20.6 citations per article, according to information from the WoS search engine on 7 December 2021.

Machining appears in $40 \%$ of the studies, including turning with $38 \%$ and drilling with $31 \%$ of the machining studies, the most trending topics present. On the other hand, $75 \%$ of the selected machining studies include sustainable cooling, 63\% for dry machining, and 19\% for cryogenic cooling and MQL. In addition, studies on the replacement of conventional fluids with biodegradable oils are emerging. Studies involving multi-material components are also abundant. Within this group, the joining of dissimilar materials and the machining of multi-material parts are identified as topics of interest, including $46 \%$ of the studies addressing multi-materials. The multi-material combination involved in most studies is the metal-metal combination, included in $62 \%$ of the studies involving multi-materials, followed by AMMs, which are present in $31 \%$.

Finally, additive manufacturing is another subject identified as increasing in interest and appears in $18 \%$ of the selected studies. The work is supported by tables summarising the main topics covered, and summarising the most cited articles on sustainable machining and cooling, multi-materials or hybrid components and additive manufacturing.

Author Contributions: Conceptualisation, E.M.R. and D.B.; methodology, E.M.R. and D.B; formal analysis, E.M.R., D.B., R.M.L.-P. and M.A.S.-N.; investigation, D.B.; resources, E.M.R.; writingoriginal draft preparation, D.B. and E.M.R.; writing-review and editing, E.M.R., D.B., R.M.L.-P. and M.A.S.-N.; visualisation, E.M.R., D.B., R.M.L.-P. and M.A.S.-N.; supervision, E.M.R.; project administration, E.M.R.; funding acquisition, E.M.R. and M.A.S.-N. All authors have read and agreed to the published version of the manuscript.

Funding: This work has been financed in part by the Spanish Ministry of Science, Innovation and Universities (Project RTI2018-102215-B-I00), by the Industrial Engineering School-UNED (REF2021ICF04), by the Master in Advanced Manufacturing Engineering and by Technical School of Engineering of the Pontifical University of Comillas.

Data Availability Statement: Not applicable.

Acknowledgments: The authors thank the support given by the Industrial Production and Manufacturing Engineering (IPME) Research Group and by the Master of Manufacturing Advanced Engineering.

Conflicts of Interest: The authors declare no conflict of interest.

\section{References}

1. Parlamento Europeo. Emisiones de $\mathrm{CO}_{2}$ de Los Coches. Available online: https://www.europarl.europa.eu/news/es/headlines/ society /20190313STO31218/emisiones-de-co2-de-los-coches-hechos-y-cifras-infografia (accessed on 12 May 2021).

2. ACARE: Protecting the Environment and the Energy Supply. Available online: https://www.eea.europa.eu/highlights/noimprovements-on-average-co2 (accessed on 12 May 2021).

3. Regulation (EU). Setting $\mathrm{CO}_{2}$ Emission Performance Standards for New Heavy-Duty Vehicles. Available online: https:/ / eur-lex. europa.eu/eli/reg/2019/1242/oj (accessed on 12 May 2021).

4. European Commission: Driving Clean Mobility. Available online: https://ec.europa.eu/commission/presscorner/detail/en/ MEMO_17_4243 (accessed on 26 October 2020).

5. Airbus Sustainability. Decarbonisation. Available online: https://www.airbus.com/company/sustainability/environment/ climate-change/decarbonisation.html (accessed on 12 May 2021).

6. Comisión Europea; Una Estrategia de Aviación Para Europa. Available online: https:/ / eur-lex.europa.eu/legal-content/ES/ TXT/PDF/?uri=CELEX:52015DC0598\&from=EN (accessed on 26 October 2020).

7. ACARE. Available online: https://www.acare4europe.org/sites/acare4europe.org/files/document/Flightpath2050_Final.pdf (accessed on 12 May 2021). 
8. ACARE: Strategic Research \& Innovation Agenda. 2017. Available online: https://www.acare4europe.org/sria/flightpath-2050 -goals / protecting-environment-and-energy-supply-0 (accessed on 26 October 2020).

9. Boeing Global Environment Report. 2020. Available online: http://www.boeing.com/principles/environment/index.page (accessed on 7 September 2020).

10. European Aviation Environmental Report. 2019. Available online: https://ec.europa.eu/transport/sites/transport/files/2019 -aviation-environmental-report.pdf (accessed on 26 October 2020).

11. Intergovernmental Panel on Climate Change (IPCC): Summary for Policymakers. Available online: https://www.ipcc.ch/site/ assets/uploads/sites/2/2019/05/SR15_SPM_version_report_LR.pdf (accessed on 19 March 2021).

12. Reducing Emissions from Shipping Sector. Available online: https://ec.europa.eu/clima/policies/transport/shipping_en (accessed on 2 November 2020).

13. IMO. Reducing Greenhouse Gas Emissions from Ships. Available online: https://www.imo.org/en/MediaCentre/HotTopics/ Pages/Reducing-greenhouse-gas-emissions-from-ships.aspx (accessed on 12 May 2021).

14. ICAO. Economic Impacts of COVID-19 on Civil Aviation. Available online: https://www.icao.int/sustainability/Pages/ Economic-Impacts-of-COVID-19.aspx (accessed on 14 April 2021).

15. ACEA. COVID-19 Impact on EU Automobile Production, up Until September 2020. Available online: https://www.acea.be/ news/article/interactive-map-covid-19-impact-on-eu-automobile-production-up-until-septem (accessed on 12 May 2021).

16. Maria Rubio, E.; Villeta, M.; Luis Valencia, J.; de Pipaon, J. Cutting Cutting parameter selection for efficient and sustainable repair of holes made in hybrid Mg-Ti-Mg component stacks by dry drilling operations. Materials 2018, 11, 1369. [CrossRef] [PubMed]

17. Rubio, E.M.; Villeta, M.; Valencia, J.L.; de Pipaón, J.M.S. Experimental study for improving the repair of magnesium-aluminium hybrid parts by turning processes. Metals 2018, 8, 59. [CrossRef]

18. Berzosa, F.; de Agustina, B.; Rubio, E.M. Tool Selection in Drilling of Magnesium UNSM11917 Pieces under Dry and MQL Conditions Based on Surface Roughness. Procedia Eng. 2017, 184, 117-127. [CrossRef]

19. Raugei, M.; Morrey, D.; Hutchinson, A.; Winfield, P. A coherent life cycle assessment of a range of lightweighting strategies for compact vehicles. J. Clean. Prod. 2015, 108, 1168-1176. [CrossRef]

20. Mavhungu, S.T.; Akinlabi, E.T.; Onitiri, M.A.; Varachia, F.M. Aluminum Matrix Composites for Industrial Use: Advances and Trends. Procedia Manuf. 2017, 7, 178-182. [CrossRef]

21. Soo, V.K.; Peeters, J.; Paraskevas, D.; Compston, P.; Doolan, M.; Duflou, J.R. Sustainable aluminium recycling of end-of-life products: A joining techniques perspective. J. Clean. Prod. 2018, 178, 119-132. [CrossRef]

22. Stein, S.; Wedler, J.; Rhein, S.; Schmidt, M.; Koerner, C.; Michaelis, A.; Gebhardt, S. A process chain for integrating piezoelectric transducers into aluminum die castings to generate smart lightweight structures. Results Phys. 2017, 7, 2534-2539. [CrossRef]

23. Ares, P.F.M.; Rodríguez-Parada, L.; Gómez-Parra, Á.; Ponce, M.B. Characterization and defect analysis of machined regions in Al-SiC metal matrix composites using an abrasivewater jet machining process. Appl. Sci. 2020, 10, 1512. [CrossRef]

24. Lahdo, R.; Springer, A.; Pfeifer, R.; Kaierle, S.; Overmeyer, L. High-power laser welding of thick steel-aluminum dissimilar joints. Phys. Procedia 2016, 83, 396-405. [CrossRef]

25. Cirillo, P.; Marino, A.; Natale, C.; Di Marino, E.; Chiacchio, P.; De Maria, G. A low-cost and flexible solution for one-shot cooperative robotic drilling of aeronautic stack materials. IFAC Pap. 2017, 50, 4602-4609. [CrossRef]

26. Kulkarni, S.; Edwards, D.J.; Parn, E.A.; Chapman, C.; Aigbavboa, C.O.; Cornish, R. Evaluation of vehicle lightweighting to reduce greenhouse gas emissions with focus on magnesium substitution. J. Eng. Des. Technol. 2018, 16, 869-888. [CrossRef]

27. Suhaimi, M.A.; Yang, G.-D.; Park, K.-H.; Hisam, M.J.; Sharif, S.; Kim, D.-W. Effect of Cryogenic Machining for Titanium Alloy Based on Indirect, Internal and External Spray System. Procedia Manuf. 2018, 17, 158-165. [CrossRef]

28. García-Martínez, E.; Miguel, V.; Martínez-Martínez, A.; Manjabacas, M.C.; Coello, J. Sustainable Lubrication Methods for the Machining of Titanium Alloys: An Overview. Materials 2019, 12, 3852. [CrossRef] [PubMed]

29. Uhlmann, E.; Kersting, R.; Klein, T.B.; Cruz, M.F.; Borille, A.V. Additive Manufacturing of Titanium Alloy for Aircraft Components Procedia CIRP 2015, 35, 55-60. [CrossRef]

30. Denkena, B.; Jacob, S. Approach for Increasing the Resource Efficiency for the Production Process of Titanium Structural Components. Procedia CIRP 2015, 35, 45-49. [CrossRef]

31. Hot, J.; Dasque, A.; Topalov, J.; Mazars, V.; Ringot, E. Titanium valorization: From chemical milling baths to air depollution applications. J. Clean. Prod. 2020, 249, 119344. [CrossRef]

32. Liberati, A.; Altman, D.G.; Tetzlaff, J.; Mulrow, C.; Gøtzsche, P.C.; Ioannidis, J.P.A.; Clarke, M.; Devereaux, P.J.; Kleijnen, J.; Moher, D. The PRISMA statement for reporting systematic reviews and meta-analyses of studies that evaluate health care interventions: Explanation and elaboration. PLoS Med. 2009, 6, e1000100. [CrossRef]

33. Chris Woolston Impact factor abandoned by Dutch university in hiring and promotion decisions. Nature 2021, 595, 462. [CrossRef]

34. Koler-Povh, T.; Južnič, P.; Turk, G. Impact of open access on citation of scholarly publications in the field of civil engineering. Scientometrics 2014, 98, 1033-1045. [CrossRef]

35. Baraniuk, R.G.; Burrus, C.S.; Thierstein, E.J. IEEE-SPS and connexions-An open access education collaboration. IEEE Signal Process. Mag. 2007, 24, 6-8. [CrossRef]

36. Guédon, J.-C. Open Access: Toward the Internet of the Mind. Bp. Open Access Initiat. 2017, 23, 1-36.

37. Inefuku, H.W. Globalization, Open Access, and the Democratization of Knowledge. Educ. Rev. 2017, 52, 62-63.

38. Budapest Open Access Initiative. Available online: https:/ / www.budapestopenaccessinitiative.org/ (accessed on 29 June 2021) 
39. Hamel, R.E. The dominance of English in the international scientific periodical literature and the future of language use in science. AILA Rev. 2007, 20, 53-71. [CrossRef]

40. Montgomery, S.L. English and Science: Realities and issues for translation in the age of an expanding lingua franca. J. Spec. Transl. 2009, 11, 6-16.

41. Li, K.; Rollins, J.; Yan, E. Web of Science use in published research and review papers 1997-2017: A selective, dynamic, crossdomain, content-based analysis. Scientometrics 2018, 115, 1-20. [CrossRef] [PubMed]

42. Martín-Martín, A.; Orduna-Malea, E.; Thelwall, M.; Delgado López-Cózar, E. Google Scholar, Web of Science, and Scopus: A systematic comparison of citations in 252 subject categories. J. Informetr. 2018, 12, 1160-1177. [CrossRef]

43. Shukla, A.K.; Janmaijaya, M.; Abraham, A.; Muhuri, P.K. Engineering applications of artificial intelligence: A bibliometric analysis of 30 years (1988-2018). Eng. Appl. Artif. Intell. 2019, 85, 517-532. [CrossRef]

44. Cancino, C.; Merigó, J.M.; Coronado, F.; Dessouky, Y.; Dessouky, M. Forty years of Computers \& Industrial Engineering: A bibliometric analysis. Comput. Ind. Eng. 2017, 113, 614-629. [CrossRef]

45. Web of Science. Available online: https://clarivate.com/webofsciencegroup/solutions/web-of-science/ (accessed on 19 March 2021).

46. Hassan, S.F.; Ogunlakin, N.O.; Al-Aqeeli, N.; Nouari, S.; Baig, M.M.A.; Patel, F. Development of tensile-compressive asymmetry free magnesium based composite using $\mathrm{TiO}_{2}$ nanoparticles dispersion. J. Mater. Res. 2018, 33, 130-137. [CrossRef]

47. Saheb, N.; Hayat, U.; Hassan, S.F. Recent advances and future prospects in spark plasma sintered alumina hybrid nanocomposites Nanomaterials 2019, 9, 1607. [CrossRef]

48. Mazaheri, Y.; Jalilvand, M.M.; Heidarpour, A.; Jahani, A.R. Tribological behavior of $\mathrm{AZ}_{31} / \mathrm{ZrO}_{2}$ surface nanocomposites developed by friction stir processing. Tribol. Int. 2020, 143, 106062. [CrossRef]

49. Liu, B.Y.; Liu, F.; Yang, N.; Zhai, X.B.; Zhang, L.; Yang, Y.; Li, B.; Li, J.; Ma, E.; Nie, J.F.; et al. Large plasticity in magnesium mediated by pyramidal dislocations. Science 2019, 364, 73-75. [CrossRef] [PubMed]

50. Gupta, M.K.; Song, Q.; Liu, Z.; Sarikaya, M.; Jamil, M.; Mia, M.; Kushvaha, V.; Singla, A.K.; Li, Z. Ecological, economical and technological perspectives based sustainability assessment in hybrid-cooling assisted machining of Ti-6Al-4 V alloy. Sustain. Mater. Technol. 2020, 26, e00218. [CrossRef]

51. Gullino, A.; Matteis, P.; D’Aiuto, F. Review of Aluminum-To-Steel Welding Technologies for Car-Body Applications. Metals 2019, 9, 315. [CrossRef]

52. Lockett, H.; Ding, J.; Williams, S.; Martina, F. Design for Wire plus Arc Additive Manufacture: Design rules and build orientation selection. J. Eng. Des. 2017, 28, 568-598. [CrossRef]

53. Yang, K.; He, C.; Huang, Q.; Huang, Z.Y.; Wang, C.; Wang, Q.; Liu, Y.J.; Zhong, B. Very high cycle fatigue behaviors of a turbine engine blade alloy at various stress ratios. Int. J. Fatigue 2017, 99, 35-43. [CrossRef]

54. Chantzis, D.; Liu, X.; Politis, D.J.; El Fakir, O.; Chua, T.Y.; Shi, Z.; Wang, L. Review on additive manufacturing of tooling for hot stamping. Int. J. Adv. Manuf. Technol. 2020, 109, 87-107. [CrossRef]

55. Popov, V.; Katz-Demyanetz, A.; Garkun, A.; Muller, G.; Strokin, E.; Rosenson, H. Effect of Hot Isostatic Pressure treatment on the Electron-Beam Melted $\mathrm{Ti}_{6} \mathrm{Al}_{4} \mathrm{~V}$ specimens. Procedia Manuf. 2018, 21, 125-132. [CrossRef]

56. Heinz, S.; Eifler, D. Crack initiation mechanisms of $\mathrm{Ti}_{6} \mathrm{Al}_{4} \mathrm{~V}$ in the very high cycle fatigue regime. Int. J. Fatigue 2016, 93, 301-308. [CrossRef]

57. Xu, F.; Dhokia, V.; Colegrove, P.; McAndrew, A.; Williams, S.; Henstridge, A.; Newman, S.T. Realisation of a multi-sensor framework for process monitoring of the wire arc additive manufacturing in producing $\mathrm{Ti}_{6} \mathrm{Al}_{4} \mathrm{~V}$ parts. Int. J. Comput. Integr. Manuf. 2018, 31, 785-798. [CrossRef]

58. Mitchell, J.; Crow, N.; Nieto, A. Effect of surface roughness on pitting corrosion of AZ 31 MG alloy. Metals 2020, 10, 651. [CrossRef]

59. Nikolić, R.R.; Djoković, J.M.; Hadzima, B.; Ulewicz, R. Spot-weld service life estimate based on application of the interfacial crack concept y. Materials 2020, 13, 2976. [CrossRef] [PubMed]

60. Widener, C.A.; Ozdemir, O.C.; Carter, M. Structural repair using cold spray technology for enhanced sustainability of high value assets. Procedia Manuf. 2018, 21, 361-368. [CrossRef]

61. Blanco, D.; Rubio, E.M.; de Pipaón, J.M.S.; Marín, M.M. Thicknesses/roughness relationship in mg-al-mg and mg-ti-mg hybrid component plates for drilled aeronautical lightweight parts. Appl. Sci. 2020, 10, 8208. [CrossRef]

62. Lee, C.A.; Lee, M.G.; Seo, O.S.; Nguyen, N.T.; Kim, J.H.; Kim, H.Y. Cyclic behavior of AZ 31 B Mg: Experiments and non-isothermal forming simulations. Int. J. Plast. 2015, 75, 39-62. [CrossRef]

63. Baghdadi, A.H.; Selamat, N.F.M.; Sajuri, Z. Effect of tool offsetting on microstructure and mechanical properties dissimilar friction stir welded Mg-Al alloys. In IOP Conference Series: Materials Science and Engineering; IOP Publishing: Bristol, UK, 2017; Volume 238.

64. Singaravel, B.; Shekar, K.C.; Reddy, G.G.; Prasad, S.D. Experimental investigation of vegetable oil as dielectric fluid in Electric discharge machining of $\mathrm{Ti}_{6} \mathrm{Al}_{4} \mathrm{~V}$. Ain Shams Eng. J. 2020, 11, 143-147. [CrossRef]

65. Béjar, S.M.; Vilches, F.J.T.; Gamboa, C.B.; Hurtado, L.S. Parametric analysis of macro-geometrical deviations in dry turning of UNS A97075 (Al-Zn) alloy. Metals 2019, 9, 1141. [CrossRef]

66. Béjar, S.M.; Vilches, F.J.T.; Gamboa, C.B.; Hurtado, L.S. Fatigue behavior parametric analysis of dry machined uns a97075 aluminum alloy. Metals 2020, 10, 631. [CrossRef]

67. Hassan, S.F.; Nasirudeen, O.O.; Al-Aqeeli, N.; Saheb, N.; Patel, F.; Baig, M.M.A. Magnesium-nickel composite: Preparation, microstructure and mechanical properties. J. Alloy. Compd. 2015, 646, 333-338. [CrossRef] 
68. Yip-Hoi, D.; Gill, D.; Gahan, J.; Travis, G.; MacKaay, L. Material stiffness and cutting parameters for honeycomb aluminum sandwich panel: A comparison with bulk material. Procedia Manuf. 2019, 34, 385-392. [CrossRef]

69. Bejger, A.; Gawdzinska, K. An Attempt to Use the Coherence Function for Testing the Structure of Saturated Composite Castings. Metalurgija 2015, 54, 361-364.

70. Bermudo, C.; Trujillo, F.J.; Herrera, M.; Sevilla, L. Parametric analysis of the Ultimate Tensile Strength in dry machining of UNS A97075 Alloy. Procedia Manuf. 2017, 13, 81-88. [CrossRef]

71. Gomez-Parra, A.; Sanz, A.; Gamez, A.J. Evaluation of the functional performance in turned workpieces: Methodology and application to UNS A92024-T3. Materials 2018, 11, 1264. [CrossRef] [PubMed]

72. Dimitrov, D.; Uheida, E.; Oosthuizen, G.; Blaine, D.; Laubscher, R.; Sterzing, A.; Blau, P.; Gerber, W.; Damm, O.F.R.A. Manufacturing of high added value titanium components. A South African perspective. IOP Conf. Ser. Mater. Sci. Eng. 2018, $430,12009$. [CrossRef]

73. Krolczyk, G.M.; Maruda, R.W.; Krolczyk, J.B.; Wojciechowski, S.; Mia, M.; Nieslony, P.; Budzik, G. Ecological trends in machining as a key factor in sustainable production-A review. J. Clean. Prod. 2019, 218, 601-615. [CrossRef] 